\title{
Genetic localisation of the RP2 type of X linked retinitis pigmentosa in a large kindred
}

\author{
A F Wright, S S Bhattacharya, M A Aldred, M Jay, A D Carothers, N S T Thomas, A C Bird,
} B Jay, H J Evans

\begin{abstract}
Genetic linkage and deletion studies have led to the proposal that there are at least two loci on the $X$ chromosome which are responsible for $\mathbf{X}$ linked retinitis pigmentosa (XLRP). One locus $(R P 3)$ has been closely defined by genetic linkage and deletion analyses and localised to the region between the ornithine transcarbamylase (OTC) and chronic granulomatous disease $(C Y B B)$ loci in Xp21.1p11.4. The other locus $(R P 2)$ has been assigned by linkage analysis alone to region Xp11.4-p11.2, but its localisation is less well defined. The results of a multipoint linkage analysis of a single large XLRP kindred using eight informative loci provide further evidence on the localisation of $R P 2$ to this region. The maximum likelihood location of this locus shows a multipoint lod score of 7.17 close to DXS255 (in Xp11.22) and TIMP (in Xp11.3-p11.23), neither of which show recombination with $R P 2$, in an area extending from $2 \mathrm{cM}$ proximal to $D X S 7$. to 1 cM distal to DXS14 (approximate $95 \%$ confidence limits).
\end{abstract}

$\mathrm{X}$ linked retinitis pigmentosa (XLRP) is a severe form of outer retinal dystrophy characterised by onset of night blindness in the first or second decade followed by progressive narrowing of the visual fields

Medical Research Council Human Genetics Unit, Western General Hospital, Crewe Road, Edinburgh EH4 2XU.

A F Wright, M A Aldred, A D Carothers, H J Evans

Department of Clinical Ophthalmology, University of London, Moorfields Eye Hospital, London ECIV 2PD. M Jay, A C Bird, B Jay

Institute of Medical Genetics, University of Wales College of Medicine, Heath Park, Cardiff CF4 4XN. N S T Thomas

Department of Human Genetics, University of Newcastle upon Tyne, 19 Claremont Place, Newcastle upon Tyne NE2 4AA.

S S Bhattacharya

Correspondence to Dr Wright.

Received for publication 4 December 1990.

Accepted for publication 3 January 1991. and usually loss of central vision before the fourth decade. At least 14 to $15 \%$ of families and 15 to $28 \%$ of retinitis pigmentosa patients in the UK have the $X$ linked disorder ${ }^{12}$ so that the population prevalence is in the region of 1 in 10000 to 30000 .

XLRP was first mapped to the proximal short arm of the $\mathrm{X}$ chromosome by genetic linkage to DXS7, localised to Xp11.4-p11.3. ${ }^{3}$ Subsequent linkage studies have supported locations both proximal ${ }^{4-9}$ and distal $^{10-13}$ to the DXS7 locus. The situation was clarified by a heterogeneity analysis of 62 XLRP kindreds from nine centres, in which it was shown that the overall likelihood was $6.4 \times 10^{9}: 1$ in favour of two loci versus a single XLRP locus. ${ }^{14}$ The majority of families (60 to $75 \%$ ) were associated with an RP3 locus at 1 to $4 \mathrm{cM}$ distal to OTC, but 25 to $40 \%$ of families were consistent with an RP2 locus localised to a broader region between $3 \mathrm{cM}$ proximal to $D X S 7$ and $1 \mathrm{cM}$ distal to the centromeric clone $D X Z 1$, representing about $16 \mathrm{cM}$ on the genetic map. ${ }^{14}$ There was some additional evidence for a third locus between DXS28 and DXS164, ${ }^{14}$ but evidence from patients with deletions in this region tends not to support this. ${ }^{15}$

The site of the RP3 locus has been further defined by the analysis of two patients with $\mathrm{X}$ chromosomal deletions showing complex phenotypes, including retinitis pigmentosa. ${ }^{16} 17$ The available evidence from this source localises $R P 3$ to a small ( $<400 \mathrm{~kb}$ ) region between $C G D$ and the proximal $\mathrm{BB}$ deletion breakpoint. ${ }^{15}$ No deletions have been found in association with the RP2 locus.

This study presents the results of a linkage analysis of a large XLRP kindred described previously, ${ }^{18}{ }^{19}$ in which the gene responsible is consistent with an RP2 location and which refines the localisation of this locus.

Materials and methods ASCERTAINMENT AND DIAGNOSIS OF FAMILY MEMBERS The $M$ kindred (RP22, F15) was ascertained through the Genetic Clinic, Moorfields Eye Hospital, London. Diagnoses were made by ophthalmological examination including fundus examination, visual field tests, electroretinogram, and, in the case of at risk females, by photopic flicker sensitivity. ${ }^{19}$ The diagnoses were 


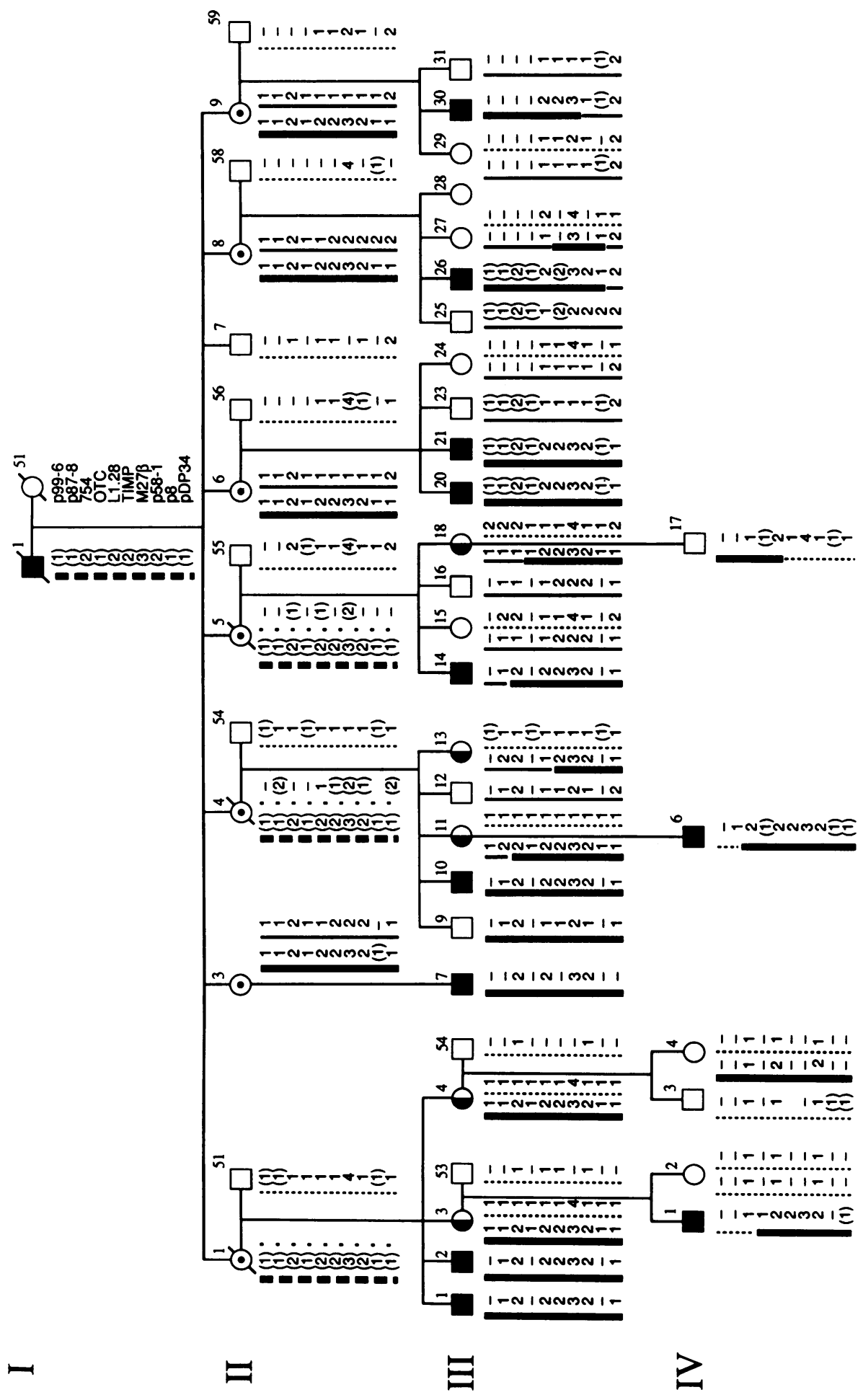


as described previously ${ }^{18}{ }^{19}$ with the exception of one at risk female (III-29, fig 1) who on re-evaluation was found to show only equivocal evidence of the carrier state so was reclassified as genetic status unknown.

\section{DNA METHODS}

DNA was extracted from whole blood by the method of Kunkel et al. ${ }^{20}$ It was digested with restriction endonuclease using 3 to 5 units $\mu \mathrm{g}^{-1}$ DNA, separated by gel electrophoresis in $0.8 \%$ agarose and $1 \times \mathrm{TBE}$ buffer, and transferred to nylon (Genescreen Plus, Nytran) filters by the method of Southern. ${ }^{21}$ Probes were labelled with and without isolation of the insert in low melting temperature agarose, by random priming or nick translation, hybridised, and washed at $65^{\circ} \mathrm{C}$ as described previously. ${ }^{6}$ The TIMP polymorphisms were analysed as described by Aldred and Wright ${ }^{22}$ by means of the polymerase chain reaction, followed by digestion with $B g I I$ and $B g I I I$, agarose gel electrophoresis and staining with ethidium bromide. The combined heterozygosity at this locus is $68 \% .^{22}$ The probes used and their associated polymorphisms are shown in table 1 .

\section{LINKAGE ANALYSIS}

Linkage was analysed using the LINKAGE program package. ${ }^{24}$ Serial four point analyses were run using the LINKMAP sub-routine and the resultant recombination fractions were converted to a linear genetic map of 50 points using the Kosambi mapping function. The multipoint lod scores were combined at each of the 50 genetic map points over all analyses. The genetic map included fixed locations for the eight informative loci (DXS164, DXS84, DXS7, TIMP, $D X S 255, D X S 14, D X S 1$, and $D X Y S 1$ ) as shown in table 1. Uninformative loci included DXS41, OTC, $O A T L 1$, and DXS146. The likelihoods were used to compute the posterior probability of linkage to $R P 3$ (set at $-23 \pm 2 \mathrm{cM}$ ) and $R P 2$ (set at $0 \pm 10 \mathrm{cM}$ ) respectively, after integration over the multipoint likelihood curve in these regions.

\section{Results}

TWO POINT ANALYSES

The results of two point analyses are shown in table 2 . Two loci, located in Xpl1.22 and Xpl1.3-pl1.23 respectively, show no evidence of recombination with $X L R P$ in this kindred, namely $D X S 255(\mathrm{Zmax}=6.92)$ and $\operatorname{TIMP}(\mathrm{Zmax}=4 \cdot 14)$. By contrast, $\mathrm{Xp} 21$ loci such as DXS164 and DXS84, both of which are closely linked to $R P 3$, show no evidence of linkage to $X L R P$ in this kindred $(\theta \max =0.50,0.40 ; Z \max =0.00$, 0.05). Probe DXS7 (Xp11.4-p11.3) shows significant evidence of linkage to $X L R P$ at a recombination fraction $(\theta \max )$ of $0.08(Z \max =4.21)$, as does the proximal Xp locus DXS14 (Xpl1.21) $(\theta \max =0.07$, $\mathrm{Zmax}=2 \cdot 85)$. The proximal $\mathrm{Xq}$ locus $D X S 1$ $\mathrm{Xq11.2-q12)}$ shows no evidence of recombination with $X L R P$ in the $M$ kindred, although this is not statistically significant $(\theta \max =0.00, Z \max =1 \cdot 8)$, while the more distal long arm locus DXYS 1 , situated close to the choroideremia gene in Xq21, shows only loose linkage to $X L R P(\theta \max =0 \cdot 29, \mathrm{Z} \max =0 \cdot 50)$.

Table 1 Table of probes and their associated polymorphisms used in this study. The chromosomal assignment of each locus is shown together with their assumed locations on a linear genetic map based on the data of Ott et al ${ }^{14}$ and Mahtani and Willard. ${ }^{23}$ The TIMP locus was amplified by means of the polymerase chain reaction as described by Aldred and Wright. ${ }^{22}$

\begin{tabular}{|c|c|c|c|c|c|}
\hline Locus & Probe & Location $(\mathbf{c M})$ & RFLP & Fragment size & Frequency \\
\hline $\begin{array}{l}\text { DXS164 } \\
\text { DXS84 } \\
\text { DXS7 } \\
T I M P\end{array}$ & $\begin{array}{l}\text { pERT } 87-8 \\
754 \\
\text { L1.28 }\end{array}$ & $\begin{array}{l}\text { Xp21.2(-32.1) } \\
\text { Xp21.1 }(-28 \cdot 0) \\
\text { Xp11.4-p11.3 }(-13 \cdot 0) \\
\text { Xp11.3-p11.23(-3.0) }\end{array}$ & $\begin{array}{l}\text { TaqI } \\
\text { PstI } \\
\text { TaqI } \\
\text { BglII } \\
\text { BglI }\end{array}$ & $\begin{array}{l}1 \cdot 1,2 \cdot 7 / 3 \cdot 8 \\
12 \cdot 0 / 9 \cdot 0 \\
12 \cdot 0 / 9 \cdot 0 \\
3 \cdot 1 / 3 \cdot 0 \\
2 \cdot 6 / 1 \cdot 9 / 0 \cdot 7\end{array}$ & $\begin{array}{l}0.74 / 0 \cdot 26 \\
0.62 / 0 \cdot 38 \\
0.68 / 0 \cdot 32 \\
0.66 / 0.34 \\
0.55 / 0.45\end{array}$ \\
\hline $\begin{array}{l}\text { DXS } 255 \\
\text { DXS14 } \\
D X S 1 \\
D X Y S 1 X\end{array}$ & $\begin{array}{l}\text { M27ß } \\
\text { p58-1 } \\
\text { p8 } \\
\text { pDP34 }\end{array}$ & $\begin{array}{l}\text { Xp11.22 (0) } \\
\text { Xp11.21 }(+6) \\
\text { Xq11.2-q12 }(+20 \cdot 0) \\
\text { Xq21.31 }(-30 \cdot 0)\end{array}$ & $\begin{array}{l}\text { PstI } \\
\text { MspI } \\
\text { TaqI } \\
\text { TaqI }\end{array}$ & $\begin{array}{l}\text { Variable } \\
4 \cdot 0 / 2 \cdot 5 \\
15 \cdot 0 / 9 \cdot 0 \\
11 \cdot 0 / 12 \cdot 0\end{array}$ & $\begin{array}{l}\text { Variable } \\
0 \cdot 65 / 0 \cdot 35 \\
0 \cdot 84 / 0 \cdot 16 \\
0.60 / 0 \cdot 40\end{array}$ \\
\hline
\end{tabular}

Table 2 Results of two point linkage analysis between $X$ linked retinitis pigmentosa and eight polymorphic markers in the $M$ kindred. The maximum likelihood values of the recombination fraction $(\theta \max )$ and lod score (Zmax) are shown.

\begin{tabular}{|c|c|c|c|c|c|c|c|c|c|}
\hline Locus & 0.00 & 0.01 & 0.05 & $0 \cdot 10$ & 0.20 & 0.30 & 0.40 & $6 \max$ & $Z_{\max }$ \\
\hline $\begin{array}{l}\text { DXS164 } \\
D X S 84 \\
D X S 7 \\
T I M P \\
D X S 255 \\
D X S 14 \\
D X S 1 \\
D X Y S 1\end{array}$ & $\begin{array}{l}-\infty \\
-\infty \\
-\infty \\
4 \cdot 14 \\
6 \cdot 92 \\
-\infty \\
1 \cdot 06 \\
-\infty\end{array}$ & $\begin{array}{r}-8.02 \\
-3.66 \\
3.10 \\
4.07 \\
6.82 \\
2.40 \\
1.04 \\
-3.88\end{array}$ & $\begin{array}{r}-4.57 \\
-1.66 \\
4.11 \\
3.82 \\
6.41 \\
2.84 \\
0.97 \\
-1 \cdot 28\end{array}$ & $\begin{array}{r}-3.12 \\
-0.89 \\
4.19 \\
3.48 \\
5.87 \\
2.80 \\
0.88 \\
-0.31\end{array}$ & $\begin{array}{r}-1.71 \\
-0.26 \\
3.67 \\
2.76 \\
4.69 \\
2.38 \\
0.68 \\
0.37\end{array}$ & $\begin{array}{r}-0.92 \\
-0.01 \\
2.75 \\
1.96 \\
3.36 \\
1.75 \\
0.48 \\
0.50\end{array}$ & $\begin{array}{r}-0.39 \\
0.05 \\
1.53 \\
1.05 \\
1.82 \\
0.96 \\
0.25 \\
0.36\end{array}$ & $\begin{array}{l}0.50 \\
0.40 \\
0.08 \\
0.00 \\
0.00 \\
0.07 \\
0.00 \\
0.29\end{array}$ & $\begin{array}{l}0.00 \\
0.05 \\
4.21 \\
4.14 \\
6.92 \\
2.85 \\
1.06 \\
0.50\end{array}$ \\
\hline
\end{tabular}




\section{MULTIPOINT ANALYSES}

The results of the multipoint analysis are shown in fig 2. The maximum likelihood location of the XLRP locus segregating in this family is between DXS255 and TIMP $(\mathrm{Zmax}=7 \cdot 17)$ although there is a broad peak with the approximate $95 \%$ confidence limits extending between a point $2 \mathrm{cM}$ proximal to $D X S 7$ and another $1 \mathrm{cM}$ distal to $D X S 14$. These results are confirmed by reference to the pedigree shown in fig 1 . The probe results are shown and individual haplotypes inferred so that the location of crossovers can be identified. Two recombinants are found between $D X S 7$ and $R P 2$, in subjects III $\cdot 13$ and IV $\cdot 17$, neither of which are recombinant with TIMP, or other proximal probes, while the distal probes DXS164 (III-13) and DXS84 (IV·17) are also recombinant. These results are both consistent with an XLRP locus proximal to $D X S 7$. Similarly, there is a single definite recombinant with $D X S 14$ which is non-recombinant with DXS255 (III·30), supporting a location distal to DXS14.

\section{PROBABILITY OF $R P 2$ VERSUS RP3 IN THE M KINDRED} The posterior probability of an RP2 versus an RP3 locus was computed on the basis of the multipoint likelihoods. This requires assumptions firstly about the location of the RP3 locus in Xp21.1-p11.4. This locus has been defined genetically as lying $1 \mathrm{cM}$ distal to $O T C,{ }^{14}$ which is consistent with the physical mapping data. ${ }^{15}$ The weighted likelihood integral was therefore calculated using as weighting function a Gaussian prior distribution centred at $-23 \mathrm{cM}$ (fig 2) with a standard deviation of $1 \mathrm{cM}$. Similarly for $R P 2$, the locus was defined as lying within $10 \mathrm{cM}$ on either

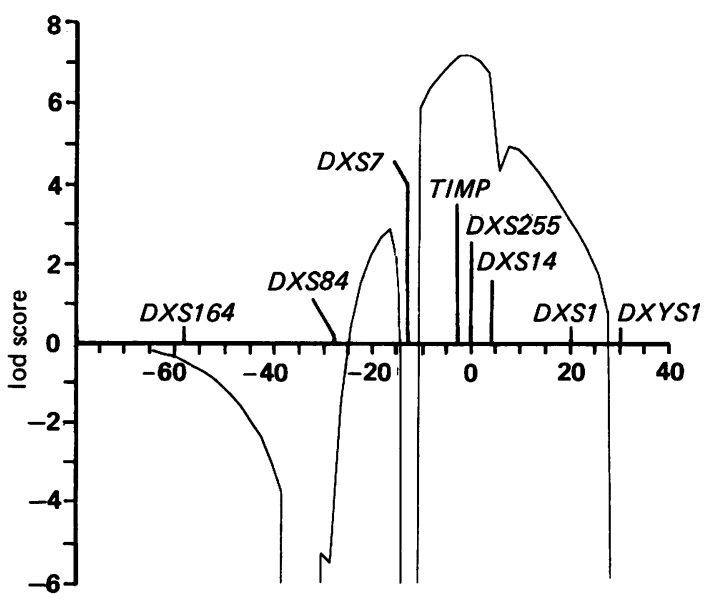

Figure 2 Results of multipoint analysis of $X$ linked retinitis pigmentosa and eight polymorphic markers in the $M$ kindred. The analysis was carried out as described in the text. The multipoint lod scores are plotted against genetic location on a linear genetic map (see table 1). side of the $D X S 255$ locus (corresponding to $-10 \mathrm{cM}$ to $+10 \mathrm{cM}$, fig 2), which is consistent with the localisation of Ott et al. ${ }^{14}$ In this case, the Gaussian weighting function was therefore centred at $0 \mathrm{cM}$ with a standard deviation of $5 \mathrm{cM}$. The prior probability of each locus was assumed to be equal and the posterior probabilities derived for $R P 2$ and $R P 3$. The results showed that the posterior probability of $R P 2$ is 1.00 in this kindred, while that for $R P 3$ is zero.

\section{Discussion}

One of the major problems in refining the genetic localisation of $R P 2$ is the presence of genetic heterogeneity and the difficulty of assigning small or moderate sized families to one or other locus. The $\mathbf{M}$ kindred, however, is large enough to provide an unambiguous assignment to either $R P 3$ or $R P 2$. The results of linkage analysis using eight informative polymorphic loci show that the posterior probability of $R P 2$ in this kindred is 1.00 , while that for $R P 3$ is zero. No recombination was observed between $R P 2$ and DXS255 $(\mathrm{Zmax}=6 \cdot 92)$ or TIMP $(\mathrm{Zmax}=4 \cdot 14)$, assigned to Xpl1.22 and Xpl1.3-pl1.23 respectively. A third locus in this region, DXS426, located in Xp11.4-p11.22, has also been found to show no evidence of recombination with $R P 2$ in this family $(Z \max =5 \cdot 13)$, as reported elsewhere. ${ }^{25}$ Low recombination frequencies were observed with two other loci in the Xp11 region, $D X S 7$ (Xp11.4-p11.3) and DXS14 (Xp11.21), which showed values of 0.08 $(Z \max =4.21)$ and $0.07(Z \max =2 \cdot 85)$ respectively. By contrast, significant recombination was found between $R P 2$ and the Xp21 loci DXS164 and DXS84, as well as with the proximal Xq marker DXYSI (table 2). The results with $D X S 164$ showed that the disease locus can be excluded for distances up to a recombination fraction of $0 \cdot 17(Z=-2 \cdot 04)$. The estimated recombination fraction between $R P 3$ and $D X S 164$ is 0.09 (see table 1 and above), which therefore excludes this locus. These results tentatively suggest that the most likely chromosomal location for $R P 2$ is in $\mathrm{R}$ band Xpl1.23, since it has been suggested that most genes are located in $R$ rather than $G$ bands, ${ }^{26}$ although it is impossible to exclude the presence of the gene in a small $R$ sub-band within a $G$ band. The matter is not of purely academic significance in the light of the ability to microdissect and isolate large numbers of clones from chromosomal bands. ${ }^{27}$

The multipoint analysis showed a broad likelihood peak between $D X S 7$ and $D X S 14$ (fig 2), consistent with the observed pattern of recombination (fig 1), which argues for a location proximal to $D X S 7$ and distal to $D X S 14$. Analysis of further RP2 families in which there is recombination between $R P 2$ and $T I M P$ or $D X S 255$ will be required to establish whether $R P 2$ is proximal or distal to these loci. 
Are there clinical features in this family that might help to distinguish RP2 from RP3 type families? This is an important question since many moderate and small families with XLRP cannot be assigned unambiguously, which complicates or excludes the use of probes for diagnostic purposes and limits the sample of families available for detecting rare recombinants and hence refining the genetic localisation. The clinical picture in affected males is relatively uniform in the $M$ family with onset of night blindness in childhood, sometimes as early as 3 years of age, followed by a progressive generalised contraction of visual fields and loss of central vision in the older men. Males show a moderate degree of myopia $(-6 \mathrm{D}$ to $-10 \mathrm{D})$. The fundus appearances and clinical features were initially described as a choroidoretinal dystrophy as distinct from retinitis pigmentosa. ${ }^{18}$ However, it is now thought to be relatively typical of XLRP, ${ }^{19}$ since choroidal atrophy is seen commonly with longstanding outer retinal atrophy. Carrier females in this family show no evidence of a tapetal reflex, in contrast to at least some RP3 families, ${ }^{28}$ but show varying degrees of peripheral retinal pigment epithelial atrophy with or without pigment migration. None of these features suggests an absolute distinction between RP3 and RP2 loci, since all the reported features have been described in association with RP3 loci, although myopia in hemizygotes may be more common with RP2 and tapetal reflex in carriers may be found exclusively with RP3. It is interesting to note that all affected males are myopic while all of their unaffected sibs are emmetropic, ${ }^{18}$ perhaps suggesting a pleiotropic effect of RP2, but if so it may be non-specific and related more to severity than to type. The wide variation in expression of XLRP both within and between many families suggests that gross clinical differences are unlikely to provide a useful means of distinguishing these loci.

This work was generously supported by the National Retinitis Pigmentosa and George Gund Foundations. We would like to thank Norman Davidson and staff for the artwork.

1 Jay M. On the heredity of retinitis pigmentosa. Br $\mathcal{J}$ Ophthalmol 1982;66:405-16.

2 Bundey S, Crews SJ. A study of retinitis pigmentosa in the City of Birmingham. II. Clinical and genetic heterogeneity. $\mathcal{f}$ Med Genet 1984;21:421-8.

3 Mandèl JL, Willard HF, Nussbaum RL, Romeo G, Puck JM, Davies KE. Report of the committee on the genetic constitution of the X chromosome. Cytogenet Cell Genet 1989;51:384-437.

4 Bhattacharya SS, Wright AF, Clayton JF, et al. Close genetic linkage between $\mathrm{X}$-linked retinitis pigmentosa and a restriction fragment length polymorphism identified by recombinant DNA probe L1.28. Nature 1984;309:253-5.

5 Friedrich $U$, Warburg $M$, Wieacker $P$, Wienker TF, Gal A, Ropers HH. X-linked retinitis pigmentosa: linkage with the centromere and a cloned DNA sequence from the proximal short arm of the X chromosome. Hum Genet 1985;71:93-9.

6 Wright AF, Bhattacharya SS, Clayton JF, et al. Linkage relationships between $\mathrm{X}$-linked retinitis pigmentosa and nine short-arm markers: exclusion of the disease locus from Xp21 and localization to between DXS7 and DXS14. Am 7 Hum Genet 1987;41:635-44.

7 Litt M, Weleber RG, Lourien EW, et al. A family study of Xlinked retinitis pigmentosa. Cytogenet Cell Genet 1987;46:651.

8 Chen JD, Halliday F, Keith G, et al. Linkage heterogeneity between X-linked retinitis pigmentosa and a map of 10 RFLP loci. Am f Hum Genet 1989;45:401-11.

9 Meitinger T, Fraser N, Lorenz B, Zrenner E, Murken J, Craig IW. Linkage of $\mathrm{X}$-linked retinitis pigmentosa to the hypervariable DNA marker M27B (DXS255). Hum Genet 1989;81: 283-6.

10 Nussbaum RL, Lewis RA, Lesko JG, Ferrell R. Mapping Xlinked ophthalmic diseases. II. Linkage relationship of $\mathrm{X}$ linked retinitis pigmentosa to $\mathrm{X}$ chromosomal short arm markers. Hum Genet 1985;70:45-50.

11 Denton MJ, Chen JD, Serravalle S, Colley P, Halliday FB, Donald J. Analysis of linkage relationships of X-linked retinitis pigmentosa with the following Xp loci: L1.28, OTC, 754, XJ1-1, pERT87 and C7. Hum Genet 1988;78:60-4.

12 Musarella MA, Burghes A, Anson-Cartwright L, et al. Localization of the gene for $\mathrm{X}$-linked recessive type of retinitis pigmentosa (XLRP) to Xp21 by linkage analysis. Am $\mathcal{J}$ Hum Genet 1988;43:484-94.

13 Wirth B, Denton MJ, Chen JD, et al. Two different genes for Xlinked retinitis pigmentosa. Genomics 1988;2:263-6.

14 Ott J, Bhattacharya SS, Chen JD, et al. Localizing multiple Xchromosome linked retinitis pigmentosa loci using multi-locus heterogeneity tests. Proc Natl Acad Sci USA 1990;87:701-4.

15 Wright AF. Towards the identification of genes in X-linked retinitis pigmentosa. Prog Retina Res 1990;9:1-31.

16 Francke U, Ochs HD, De Martinville B, et al. Minor Xp21 chromosome deletion in a male associated with expression of Duchenne muscular dystrophy, chronic granulomatous disease, retinitis pigmentosa and McLeod syndrome. Am $\mathcal{F}$ Hum Genet 1985;37:250-67.

17 de Saint-Basile G, Bohler MC, Fischer A, et al. Xp21 DNA microdeletion in a patient with chronic granulomatous disease, retinitis pigmentosa and McLeod phenotype. Hum Genet 1988;80:85-9.

18 Hoare GW. Choroido-retinal dystrophy. Br $\mathcal{f}$ Ophthalmol 1965; 49:449-59.

19 Bhattacharya SS, Clayton JF, Harper PS, et al. A genetic linkage study of a kindred with $\mathrm{X}$-linked retinitis pigmentosa. $\mathrm{Br} \mathcal{J}$ Ophthalmol 1985;69:340-7.

20. Kunkel LM, Tantravahi U, Eisenhard M, Latt SA. Regional localisation on the human X of DNA segments cloned from flow sorted chromosomes. Nucleic Acids Res 1982;10:1557-8.

21 Southern EM. Detection of specific sequences among DNA fragments separated by gel electrophoresis. F Mol Biol 1975;98: 503-17.

22 Aldred MA, Wright AF. PCR detection of existing and new polymorphism at the TIMP locus. Nucleic Acids Res 1991;19: 1165.

23 Mahtani MM, Willard HF. A primary genetic map of the pericentromeric region of the human $\mathrm{X}$ chromosome. Genomics 1988:2:294-301.

24 Lathrop GM, Lalouel JM, Julier C, Ott J. Strategies for multilocus linkage analysis in humans. Proc Natl Acad Sci USA 1984;81:3443-6.

25 Coleman M, Bhattacharya SS, Lindsay S, et al. Localization of the microsatellite probe DXS426 between DXS7 and DXS255 on Xp and linkage to X-linked retinitis pigmentosa. Am $\mathcal{F}$ Hum Genet 1990;47:935-40.

26 Bickmore WA, Sumner AT. Mammalian chromosome bandingan expression of genome organization. Trends Genet 1989;5: $144-8$.

27 Ludecke HJ, Senger G, Claussen U, Horsthemke B. Cloning defined regions of the human genome by microdissection of banded chromosomes and enzymatic amplification. Nature 1989;338:348-50.

28 Musarella MA, Anson-Cartwright L, Burghes A, Worton RG Lesko JG, Nussbaum RL. Linkage analysis of a large LatinAmerican family with $\mathrm{X}$-linked retinitis pigmentosa and metallic sheen in the heterozygote carrier. Genomics 1989;4: 601-5. 